\title{
The role of the oviduct in reproduction; our knowledge and our ignorance
}

\author{
Carl J. Pauerstein and Carlton A. Eddy \\ The Center for Research and Training in Reproductive Biology, The Department of Obstetrics \\ and Gynecology, The University of Texas Health Science Center at San Antonio, 7703 Floyd \\ Curl Drive, San Antonio, Texas 78284, U.S.A.
}

Processes essential to reproduction known to occur in the oviducts of Eutherian mammals include sperm transport, capacitation, ovum pick-up and transport, fertilization and embryo transport and nourishment. Our knowledge of these processes in our own species, man, is incomplete. The reasons underlying our lack of information concerning the physiology of the human Fallopian tube are ethical, philosophical, and technical. Although some of our failure to obtain definitive data in women has been due to ethical constraints we have also been limited philosophically by our inability to formulate the critical questions, and pragmatically by the lack of technology with which to accurately measure many biological phenomena. After more than a half century of clinical interest in female infertility, we are unable to assess accurately a single physiological function of the Fallopian tube. Our clinical armamentarium is limited to appraisals of the patency of the tube to gas or liquid, and to examination of the external appearance and texture of the tube. Even if all ethical constraints were removed, it would still be necessary to identify the important questions, design the critical experiments, and to develop the required technology.

In this essay we shall emphasize postovulatory events, specifically fertilization, ovum pickup, and ovum and embryo transport. We will discuss the pertinent physiological phenomena, and then we shall attempt to correlate tubal anatomy and physiology with clinical considerations.

\section{Physiological functions}

\section{Fertilization}

Spermatozoa await the arrival of the ovum in the oviduct for a period which in most species is less than half their potential fertile life. The fertile life of spermatozoa within the female genital tract is shorter than the motile life and varies from $12 \mathrm{~h}$ in the mouse (McGaughey, Marston \& Chang, 1968), through $30 \mathrm{~h}$ in the rabbit (Noyes \& Thibault, 1962), to $100 \mathrm{~h}$ or more in the bitch (Doak, Hall \& Dale, 1967), mare (Burkhardt, 1949) and ferret (Chang, 1965). The fertile life of spermatozoa in women has not been accurately determined but was previously estimated at 28-48 h (Cohen \& Stein, 1951; Tietze, 1960; Bedford, 1970). More recent work suggests that this in an underestimate. Ferin, Thomas \& Johansson (1973) estimated that pregnancy resulted from a coital exposure that took place $120 \mathrm{~h}$ before presumed ovulation, as judged by the $\mathrm{LH}$ peak. Although the estimated time of ovulation might have been in error, it is likely that at least $72 \mathrm{~h}$ elapsed between insemination and ovulation. Ahlgren (1975) observed motile spermatozoa in the tubal ampulla $85 \mathrm{~h}$ after coitus. However, there is no evidence that these spermatozoa retained their ability to fertilize. Definitive information concerning the fertilizing life-span of human spermatozoa is needed both for couples wishing to rely on timed abstinence for contraception, and to improve pregnancy rates in some types of infertility problem. 


\section{Ovum pick-up}

An early theory suggested that ova were drawn into the tube by a negative pressure caused by tubal peristalsis. Maia \& Coutinho (1970) resurrected this hypothesis by demonstrating negative pressures following contractions detected by intraluminal catheters placed in the human Fallopian tube. Negative pressures of $1 \mathrm{mmHg}$ were observed after antiperistaltic waves of contraction had passed the catheter moving towards the ovary. These authors speculated that suction assisted ovum pick-up by the oviduct. No evidence for suction of the ovum into the human Fallopian tube exists.

Integrated contractions of the oviduct, its accessory membranes, the fimbria, and the ovary at ovulation have been described for the rabbit, monkey and man (Westman, 1926, 1937, 1952; Blandau, 1969). Observations of women by culdoscopy or laparoscopy indicate that in the usual mechanism of ovum pick-up the fimbria and oviductal ostium are brought into contact with the ovary by contraction of the smooth muscle of the mesosalpinx and tubo-ovarian ligaments. The fimbria then move across the surface of the ovary to contact the ovum. The mucosal folds of the fimbria are densely covered with cilia. Direct ciliary contact with the cumulus surrounding the ovum seems critical to ovum pick-up. However, pregnancy can occur in women with one ovary and only the contralateral oviduct (First, 1954), and ova have been recovered from the oviduct contralateral to the ovary bearing the corpus luteum in women with normal oviducts and ovaries (Doyle, Lippes, Winters \& Margolis, 1966), suggesting that pick-up from the cul-de-sac can occur.

\section{Ovum and embryo transport}

After being conducted into the oviduct the ovum is transported first to the site of fertilization and then to the uterus. With few exceptions the overall time course of ovum transport is remarkably similar in all mammalian species examined: $3-4$ days are required for ova to travel form the ovary to the uterus. However, major differences exist in the details of entrance into and transit through various portions of the oviduct. These differences probably reflect anatomical and endocrinological differences between species.

The detailed time course of ovum transport has been examined in two species of primates in which ovulation was accurately timed, the rhesus monkey, Macaca mulatta (Eddy, Garcia, Kraemer \& Pauerstein, 1975), and the baboon, Papio anubis (Eddy, Turner, Kraemer \& Pauerstein, 1976). It was concluded that transport in the rhesus monkey required approximately 3 days during most of which ova resided in the ampulla, and then passed through the isthmus into the uterus. At about the same time Croxatto and his colleagues in Santiago, Chile utilized various criteria, including oestrogen and $\mathrm{LH}$ determinations, to approximate the time of ovulation in women. They then recovered ova from the oviducts and uteri of women operated upon at known intervals after ovulation. They found that transport of ova in women is characterized by retention in the ampulla for approximately $72 \mathrm{~h}$, followed by rapid transit through the isthmus. Ova are delivered to the endometrial cavity approximately $80 \mathrm{~h}$ after release from the follicles (Croxatto \& Ortiz, 1975; Cheviakoff et al., 1976; Croxatto et al., 1978). Thus, the detailed time course of ovum transport in women and rhesus monkeys is virtually identical. Both differ dramatically from the rabbit.

An interesting additional observation has been the prolonged retention of granulosa cells around non-fertilized tubal ova in man and non-human primates. Such similarities among primates strengthen the validity of the non-human primate as an animal model for the study of human ovum transport.

Although we have described the detailed time course of ovum transport, we know little of the mechanisms regulating ovum transport. Knowledge of these mechanisms is important to the development of contraceptive technology, and to the evaluation and treatment of infertility. In non-human primates premature entry of the embryo into the uterus prevents implantation. We 
have no evidence that this would be true in man, and we have been unable to obtain the necessary information because we lack a reliable technique to induce accelerated ovum transport in primates. In our attempts to gain some understanding of these control mechanisms, we have considered the roles of the various components and regions of the oviduct.

Role of the myosalpinx. Although it seems intuitively obvious that contractions of the myosalpinx are important in gamete and embryo transport, the precise relationships have yet to be defined. The reasons for this failure of definition are both technological and biological. Several investigators have measured oviductal contractile activity in many species by utilizing intra- and extra-luminal sensors in vivo and in vitro (Blandau, Boling, Halbert \& Verdugo, 1975). To date studies utilizing mechanical measurements of contractile activity have not shown any relationship of such parameters as intraluminal pressure or wall tension to ovum transport rates. Indeed, compounds such as ergot alkaloids, prostaglandin F-2 $\alpha$, and other agents that increase oviductal motility fail to accelerate ovum transport. Recent experiments employing arrays of suction electrodes 1-2 mm apart explain some of the failures to correlate transport rates with contractile activity. These experiments demonstrated that oviductal contractions propagate for extremely short distances, of the order of a few millimetres. Further, only the electrical bursts in the immediate vicinity of the ovum or ovum model appear to influence its transport (Hodgson, Talo \& Pauerstein, 1977). Therefore failures of mechanical systems to demonstrate clear correlations between motility and ovum transport may merely reflect the distance between the sensor and the ovum.

Role of the innervation. The dense adrenergic innervation of the oviductal isthmus, along with its prominent myosalpinx, suggested that this segment of the oviduct might function as an adrenergic sphincter. Physiological data obtained in non-primate mammals and from extirpated human Fallopian tubes supported this possibility. However, pharmacological manipulation of the adrenergic system does not disrupt normal ovum transport in non-human primates (Bodkhe \& Harper, 1972; Polidoro, Howe \& Black, 1973; Eddy \& Black, 1974; Pauerstein, Hodgson, Fremming \& Martin, 1974; Polidoro, Heilman, Culver \& Reo, 1976). Demonstrations that autotransplantation of the oviduct and ovary does not prevent normal pregnancy in the rabbit (Winston \& McClure-Browne, 1974) or in the ewe (Cohen et al., 1976) cast further doubt on the primary importance of tubal adrenergic innervation in ovum transport.

Role of the mucosa. In spite of much speculation there are no hard data which demonstrate a role for tubal secretions in ovum transport. However, it has been established that the oviductal environment provides nutrients to the developing embryos of rabbits, mice and hamsters. These experiments do not prove that normal tubal mucosa is necessary to reproduction, nor do they define the minimal requirements for embryo survival. The problem is compounded by marked differences between man and the non-human primates. In the latter species the embryo cannot develop beyond the blastocyst stage in the oviduct. In contrast, the human embryo is capable of implanting and developing to advanced stages in the Fallopian tube. Because ectopic implantation often occurs in oviducts that have been previously damaged by infectious agents, it is unlikely that a normal mucosa is necessary to the survival of the human embryo.

It has been convincingly shown that the cilia are involved in ovum pick-up and in the transport of ova into the abdominal ostium of the rabbit oviduct and to the ampullary-isthmic junction. Inhibition of muscular activity in the rabbit oviduct banishes the to-and-fro movements of cumulus masses in the ampulla, but does not alter the net velocity with which they are transported to the ampullary-isthmic junction (Halbert, Tam, Adams \& Blandau, 1976). The role of the cilia in gamete transport in the rabbit has been elucidated by utilizing surgical modification of the oviduct. The earliest pertinent work was published 50 years ago (Kuo \& Lim, 1928). A recent series of experiments in our laboratories utilized microsurgical techniques to demonstrate that reversal of $1-\mathrm{cm}$ segments of the rabbit oviductal isthmus does not interfere with normal fertility. In contrast, reversal of a similar length of ampulla completely prevents pregnancy. The cilia in the reversed segments continue to beat in their original direction, i.e. 
opposite to that of the cilia in the unaltered remaining portion of the ampulla. Ova in cumulus placed on the fimbrial surface at laparotomy are transported in normal fashion until the reversed segment of tube is encountered. Further transport is arrested at the interface between the cilia beating toward the uterus and those in the reversed segment beating toward the ovary. Displacement of such ova into the reversed segment is followed by transport in the ovarian direction until the interface is again encountered, at which time further forward movement is arrested. In contrast, in control oviducts in which $1-\mathrm{cm}$ segments were transected but not reversed, ovum transport was normal and fertility was unaltered (Eddy, Flores, Archer \& Pauerstein, 1978b). These observations suggest a crucial role for cilia in transport of ova through the rabbit ampulla, but not the isthmus.

The role of the cilia in human gamete transport and fertility is much more difficult to appraise. Brosens \& Vasquez (1976) reported a correlation between the percentage of ciliated cells on the human fimbria and normal fertility. They stated that no woman whose fimbria contained less than $54 \%$ ciliated cells conceived. G. Vasquez \& R. M. L. Winston (personal communication) have continued these studies. They have shown that tubal sterilization is associated with loss of ciliated cells, among other morphological changes. They have also observed marked deciliation with preservation of the mucosal folds in 10 women with ectopic pregnancy, in 3 women who later developed ectopic pregnancy and in 7 women who had a history of ectopic pregnancy. These observations led logically to the suggestion that deciliation is the factor common to infertility and eccyesis in such diverse conditions as reversal of sterilization, pelvic inflammatory disease, progesterone administration and use of intrauterine contraceptive devices. However, these speculations must confront the recent observation that women, but not men, with the "immotile cilia syndrome" are fertile. Persons affected with this congenital syndrome suffer with bronchitis, rhinitis and sinusitis from childhood. About half of these patients also have situs inversus totalis (Kartagener's syndrome). In this syndrome the cilia are immotile because of a nearly complete absence of dynein arms. In addition, the distribution of cilia on the respiratory mucosa is random rather than orderly. Yet a recent report demonstrated normal fertility in 2 of 3 women with this syndrome who attempted to become pregnant. There was no history of ectopic pregnancy or of abortion (Afzelius, Camner \& Mossberg, 1978). Although the oviductal cilia were not examined in these women, one would suppose that the cilia throughout the body are affected. This supposition is strengthened by a recent report of normal fertility in 4 of 5 women with Kartagener's syndrome. In 1 of these women an endocervical biopsy revealed an absence of dynein arms in the endocervical cilia (Bleau, Richer \& Bousquest, 1978). Thus it seems likely that motile cilia are not necessary to human female fertility. The final proof must await biopsy of the tubal mucosa in such a patient.

The possibility that certain regions or segments of the oviduct are critical to normal ovum transport is basic to an understanding of the control system. This question has been approached by examining the effect of resection of a given region on fertility.

Role of the utero-tubal junction. David, Brackett \& Garcia (1969) tested the concept that the utero-tubal junction was responsible for retention of ova in the rabbit oviduct by resecting 0.24 $0.5 \mathrm{~cm}$ of the uterus and $1.0-1.5 \mathrm{~cm}$ of the isthmus. Although the authors concluded that the utero-tubal junction was necessary to normal fertility, they did not include controls for the effects of transection and re-anastomosis on fertility. Work in our own laboratories demonstrated that the utero-tubal junction is not critical to reproduction in the rabbit.

Successful pregnancies obtained in about half of a group of patients treated with bilateral utero-tubal implantation suggests that the utero-tubal junction is not essential to human reproduction. In these patients, the Fallopian tubes were implanted in the uterine cavity via transverse incisions in the myometrium on the posterior aspect of the uterus, at the level of the ovarian ligaments. Thus the utero-tubal junction was excluded from the reconstructive procedure (Peterson, Musich \& Behrman, 1977).

Role of the isthmus. Hunter \& Léglise $(1971 \mathrm{a}, \mathrm{b})$ resected the oviductal isthmus in rabbits 
and swine. This procedure did not interfere with fertilization and cleavage, except for an increased incidence of polyspermic fertilization. Recently, we have demonstrated that resection of $1-\mathrm{cm}$ segments of the isthmus of rabbits does not adversely affect fertility. R. M. L. Winston \& X. Y. Boeckx (personal communication) have also examined the effects of removal of 5-30\%, $31-50 \%, 71-90 \%$ and $100 \%$ of the isthmus in rabbits. The pregnancy rate diminished with progressive shortening of the isthmus, until $50 \%$ of the length was removed. At this point an asymptote was reached and half of the animals conceived even when the entire isthmus was resected. Therefore, pregnancy can occur in rabbits in the absence of the isthmus.

Winston (1977) attempted to restore fertility in 16 women in all of whom at least $2 \mathrm{~cm}$ of isthmus were missing from each oviduct: 11 of the 16 patients experienced successful intrauterine pregnancy after tubo-cornual anastomosis. Thus resection of a significant portion of the tubal isthmus is compatible with normal reproduction in women.

Role of the ampullary-isthmic junction. The ampullary-isthmic junction has been thought to be essential to the control of ovum transport in several species. However, removal of this area in the rabbit does not interfere with normal fertility (Eddy, Antonini \& Pauerstein, 1977; Winston, Frantzen \& Oberti, 1977) and does not modify the tube-locking of ova induced by pharmacological doses of depot oestradiol (Eddy, Balmaceda \& Pauerstein, 1978a).

Gomel (1977) reported ampullary-isthmic anastomosis in 14 of 16 patients previously sterilized by the Pomeroy or the Irving technique: 8 of the patients experienced successful intrauterine pregnancies after re-anastomosis. Winston (1977) has reported similar findings. Thus, removal of the ampullary-isthmic junction does not preclude successful pregnancy in women.

Role of the ampulla. Few data are extant concerning the effects of resecting a section of ampulla. Removal of $1-\mathrm{cm}$ segments of ampulla does not interfere with fertility in the rabbit (Eddy et al., 1978b). However, R. M. L. Winston \& X. Y. Boeckx (personal communication) have shown that removal of larger segments of ampulla $(5-30 \%, 51-70 \%$ and $71-90 \%)$ does interfere with fertility. Removal of $70 \%$ of the ampulla completely prevented pregnancy. Although no clinical information concerning the effects of ampullary resection is available, the unaltered fertility seen in the rabbit following resection of small ampullary segments tends to support an encouraging prognosis following such surgery in women.

Role of the fimbria. Tuboplastic surgery designed to restore a functional abdominal tubal ostium, whether performed on pathologically damaged oviducts or following sterilization by fimbriectomy, remains the least successful reconstructive procedure. Undoubtedly this is a reflection of the highly specialized nature of the fimbria and their role in the ovum pick-up mechanism.

\section{Conclusions}

In concluding this review of current knowledge, we would like to summarize our areas of ignorance concerning human tubal physiology. With regard to the male, we need more information about the mechanism of sperm transport, the need for capacitation, and the fertilizing life-span of spermatozoa. With regard to the ovum and embryo, we know little about the mechanisms of ovum transport, the importance of synchrony between the ovary and the embryo's arrival in the uterus, and the propensity of our species to develop tubal pregnancy. With respect to the oviductal factor, we know very little about the critical length of residual oviduct required for function or which, if any, regions are critical to function.

We hope that this review has proved informative, and that some readers will be inspired to search for some of the missing information.

The original work from this laboratory was supported by NICHHD grants No. 1 P30 HD10202, No. 5 RO1 HD09309 and No. 5 RO1 HD09339, and by W.H.O. (grant No. 73039). 


\section{References}

Afzelius, B.A., Camner, P. \& Mossberg, B. (1978) On the function of cilia in the female reproductive tract. Fert. Steril. 29, 72-74.

Ahlgren, M. (1975) Sperm transport to and survival in the human fallopian tube. Gynecol. Invest. 6, 206214.

Bedford, J.M. (1970) The saga of mammalian sperm from ejaculation to syngamy. In Mammalian Reproduction, pp. 124-182. Eds H. Gibian \& E. J. Plotz. Springer-Verlag, New York.

Blandau, R.J. (1969) Gamete transport; comparative aspects. In The Mammalian Oviduct, pp. 129-162. Eds. E. S. E. Hafez \& R. J. Blandau. University of Chicago Press.

Blandau, R.J., Boling, J.L., Halbert, S. \& Verdugo, P. (1975) Methods of studying oviductal physiology. Gynecol. Invest. 6, 123-145.

Bleau, G., Richer, C.-L. \& Bosquet, D. (1978) Absence of dynein arms in cilia of endocervical cells in a fertile woman. Fert. Steril. (in press).

Bodkhe, R.R. \& Harper, M.J.K. (1972) Changes in the amount of adrenergic neurotransmitter in the genital tract of untreated rabbits, and rabbits given reserpine or iproniazid during the time of egg transport. Biol. Reprod. 6, 288-299.

Brosens, I.A. \& Vasquez, G. (1976) Fimbrial microbiopsy. J. Reprod. Med. 16, 171-178.

Burkhardt, J. (1949) Sperm survival in the genital tract of the mare. J. agric. Sci., Camb. 39, 201-203.

Chang, M.C. (1965) Fertilizing life of ferret sperm in the female tract. J. exp. Zool. 158, 87-100.

Cheviakoff, S., Diaz, S., Carril, M., Patritti, N., Croxatto, H.D., Llados, C., Ortiz, M.E. \& Croxatto, H.B. (1976) Ovum transport in women. In Ovum Transport and Fertility Regulation, pp. 416-424. Eds M. J. K. Harper, C. J. Pauerstein, C. E. Adams, E. M. Coutinho, H. B. Croxatto \& D. M. Paton. Scriptor, Copenhagen.

Cohen, B.M., Morgenthal, J.C., Davey, D.A.D., Van Niekerk, C.H., Uys, C.J., Botha, M.C., Dutoit, E., Harrison, V.C., Hickman, R., Lotter, F. \& Poole, D.M.J. (1976) Completed pregnancy following vascularised heterotopic autotransplantation of the fallopian tube in the ewe. Int. J. Fertil. 21, 153-158.

Cohen, M.R. \& Stein, I.F. (1951) Sperm survival at the estimated ovulation time. Fert. Sterih 2, 20-28.

Croxatto, H.B. \& Ortiz, M.E.S. (1975) Egg transport in the follopian tube. Gynecol. Invest. 6, $215-225$.

Croxatto, H.B., Ortiz, M.E., Diaz, S., Hess, R., Balmaceda, J. \& Croxatto, H.D. (1978) Studies on the duration of egg transport by the human oviduct. II. Ovum location at various intervals following $\mathrm{LH}$ peak. Am.J. Obstet. Gynec. (in press).

David, A., Brackett, B.G. \& Garcia, C.R. (1969) Effects of microsurgical removal of the rabbit uterotubal junction. Fert. Steril. 20, 250-257.

Doak, R.L., Hall, A. \& Dale, H.E. (1967) Longevity of spermatozoa in the reproductive tract of the bitch. $J$. Reprod. Fert. 13, 51-58.

Doyle, L.L., Lippes, J., Winters, H.S. \& Margolis, A.J. (1966) Human ova in the fallopian tube. Am. J. Obstet. Gynec. 95, 115-117.
Eddy, C.A. \& Black, D.L. (1974) Ovum transport through rabbit oviducts perfused with 6-hydroxydopamine. J. Reprod. Fert. 38, 189-191.

Eddy, C.A., Garcia, R.G., Kraemer, D.C. \& Pauerstein, C.J. (1975) Detailed time course of ovum transport in the rhesus monkey (Macaca mulatta). Biol. Reprod. 13, 363-369.

Eddy, C.A., Turner, T., Kraemer, D. \& Pauerstein, C.J. (1976) Pattern and duration of ovum transport in the baboon (Papio anubis). Obstet. Gynecol. 47, 658644.

Eddy, C.A., Antonini, R., Jr. \& Pauerstein, C.J. (1977) Fertility following microsurgical removal of the ampullary-isthmic junction in rabbits. Fert. Steril. 28, $1090-1093$.

Eddy, C.A., Balmaceda, J.P. \& Pauerstein, C.J. (1978a) Effect of resection of the ampullary-isthmic junction on estrogen induced tube locking of ova in the rabbit. Biol. Reprod. (in press).

Eddy, C.A., Flores, J.J., Archer, D.R. \& Pauerstein, C.J. (1978b) The role of cilia in fertility: an evaluation by selective microsurgical modification of the rabbit oviduct. Am. J. Obstet. Gynec. (in press).

Ferin, J., Thomas, K. \& Johansson, E.D.B. (1973) Ovulation detection. In Human Reproduction: Conception and Contraception, pp. 261-283. Eds E. S. E. Hafez \& T. Evans. Harper \& Row, New York.

First, A. (1954) Transperitoneal migration of ovum or spermatozoon. Obstet. Gynecol. 4, 431-434.

Gomel, V. (1977) Tubal reanastomosis by microsurgery. Fert. Steril. 28, 59-65.

Halbert, S.A., Tam, P.Y., Adams, R.J. \& Blandau, R.J. (1976) An analysis of the mechanisms of egg transport in the ampulla of the rabbit oviduct. Gynecol. Invest. 7, 306-320.

Hodgson, B.J., Talo, A. \& Pauerstein, C.J. (1977) Oviductal ovum surrogate movement: interrelation with muscular activity. Biol. Reprod. 16, 394-396.

Hunter, R.H.F. \& Léglise, P.C. (1971a) Tubal surgery in the rabbit: fertilization and polyspermy after resection of the isthmus. Am. J. Anat. 132, 45-52.

Hunter, R.H.F. \& Léglise, P.C. (1971a) Polyspermic fertilization following tubal surgery in pigs, with particular reference to the role of the isthmus. $J$. Reprod. Fert. 24, 233-246.

Kuo, Y.P. \& Lim, R.K.S. (1928) On the mechanism of the transportation of ova. II. Rabbit and pig oviduct. Chinese J. Physiol. 2, 389-398.

Maia, H. \& Coutinho, E.M. (1970) Peristalsis and antiperistalsis of the human fallopian tube during the menstrual cycle. Biol. Reprod. 2, 305-314.

McGaughey, R.W., Marston, J.H. \& Chang, M.C. (1968) Fertilizing life of mouse spermatozoa in the female tract. J. Reprod. Fert. 16, 147-150.

Noyes, R.W. \& Thibault, C. (1962) Endocrine factors in the survival of spermatozoa in the female reproductive tract. Fert. Steril. 13, 346-365.

Pauerstein, C.J., Hodgson, B.J., Fremming, B.D. \& Martin, J.E. (1974) Effects of sympathetic denervation of the rabbit oviduct on normal ovum transport and on transport modified by estrogen and progesterone. Gynecol. Invest. 5, 121-132. 
Peterson, E.P., Musich, J.R. \& Behrman, S.J. (1977) Uterotubal implantation and obstetric outcome after previous sterilization. Am. J. Obstet. Gynec. 128, $662-665$.

Polidoro, J.P., Howe, G.R. \& Black, D.L. (1973) The effects of adrenergic drugs on ovum transport through the rabbit oviduct. J. Reprod. Fert. 35, 331337.

Polidoro, J.P., Heilman, R.D., Culver, R.M. \& Reo, R.R. (1976) Effects of adrenergic drugs or denervation on ovum transport in rabbits. In Ovum Transport and Fertility Regulation, pp. 331-341. Eds M. J. K. Harper, C. J. Pauerstein, C. E. Adams, E. M. Coutinho, H. B. Croxatto \& D. M. Paton. Scriptor, Copenhagen.

Tietze, C. (1960) Probability of pregnancy resulting from a single unprotected coitus. Fert. Steril. 11, 485-488.

Westman, A. (1926) A contribution to the question of the transit of the ovum from ovary to uterus in rabbits. Acta obstet. gynec. scand. 5, Suppl. 3, 1-104.

Westman, A. (1937) Investigations into the transit of ova in man. J. Obstet. Gynaec. Br. Emp. 44, 821-838.

Westman, A. (1952) Investigations into the tranisport of the ovum. In Proc. Conf. Studies on Testis and Ovary, Eggs, and Sperm, pp. 163-175. Ed. E. T. Engle. Charles C. Thomas, Springfield.

Winston, R.M.L. (1977) Microsurgical tubocornual anastomosis for reversal of sterilization. Lancet $\mathbf{i}$, 284-285.

Winston, R.M.L. \& McClure-Brown, J.C. (1974) Pregnancy following autograft transplantation of fallopian tube and ovary in the rabbit. Lancet ii, 494-495.

Winston, R.M.L., Frantzen, C. \& Oberti, C. (1977) Oviduct function following resection of the ampullary-isthmic junction. Fert. Steril. 28, 284, Abstr. 